\title{
Geração de Seqüências Viáveis para Montagem Automatizada
}

Gilcina Guimarães

P.O Boaventura Netto

Ricardo M. Naveiro

Universidade do Estado do Rio de Janeiro

Campus - Rua S. Francisco Xavier, 524, RJ

COPPE/Universidade Federal do Rio de Janeiro

Cidade Universitária - Ilha do Fundão -B1.F

Palavras chave: Pesquisa Operacional, Montagem Automatizada, Teoria dos Grafos.

Keywords: Operations Research, Automatic Assembly, Graph Theory.

\section{RESUMO}

Este trabalho consiste numa aplicação das técnicas de modelagem por grafos à geração de seqüências de montagem de um produto discreto (composto de uma série de peças). Utilizamos como referência para o trabalho método desenvolvido por A. Bourjault [5] e T. Fazio e D. Whitney [6].

\section{ABSTRACT}

This work is an application of graph modelling techniques for assembly sequence generation of a discrete product. We used as reference for the work the method developed by A.Bourjault [5] with the simplifications proposed by T.Fazio and D. Whitney [6]. 


\section{Introdução}

O processo de transformação de matériaprima em produtos industrializados é denominado processo de produção ou de fabricação. Dentre as várias fases de um processo de fabricação destaca-se, por sua importância, a da montagem, que é a operação de unir peças fixando-as através de técnicas específicas, com a utilização de elementos de ligação tais como: porcas, parafusos, pinos, rebites e similares, ou por meio de soldagem, colagem, formas de montagem prensada, encaixe simples ou baseado na dilatação térmica.

A importância dos processos de montagem fica caracterizada pelo fato de que esta representa $53 \%$ do tempo total do processo de fabricação. A mão-de-obra direta envolvida em montagem em alguns tipos de produção em linha dá uma idéia da dimensão do problema (NEVINS E WHITNEY (1978) [1]):

maquinaria agrícola $30.2 \%$

veículos $33.5 \%$

máquinas ferramenta $11.0 \%$

rádio e televisão $23.9 \%$

A montagem de um produto é, então, o conjunto de ações desenvolvidas para a obtenção de um produto composto. Estas ações obedecem a uma ordem de execução denominada seqüência de montagem. As sucessivas configurações assumidas pelo produto durante o processo de montagem são ditadas pela sequiência escolhida para realização da composição do produto.

Um produto discreto (composto de várias peças) admite, habitualmente, diferentes or- dens de montagem. A cada ordem de montagem que permite a composição final correta do produto chamaremos seqüência válida (ou possivel) de montagem.

Tradicionalmente vem sendo destinado ao homem o trabalho de montagem que, por sua complexidade e manipulação detalhada, não pode ser ainda executado por um substituto adequado. Por outro lado, sendo as tarefas de montagem essencialmente repetitivas e, por conseqüência maçantes, com facilidade elas provocam fadiga e apresentam baixa confiabilidade. Nos países desenvolvidos, onde a mão-de-obra desqualificada é escassa e em processo de qualificação, a demanda por automação das operações vem aumentando (Ricardo M. Naveiro, 1987) [2].

Para os grandes lotes de produção (acima de 1 milhão de peças por ano) normalmente se adota a automação rigida da montagem, onde máquinas especializadas executam as operações de movimentação, posicionamento e união propriamente dita. Para lotes de produção anuais considerados médios $(300.000$ a 1.000 .000 de peças por ano), a solução passa a ser a automação flexível, utilizando-se manipulador programável ("robot") para execução das operaç̃os de montagem. O uso de manipuladores programáveis pressupõe a existência de duas condições básicas:

a) Compatibilidade fisica entre manipulador e componentes a serem montados. Esta compatibilidade é alcançada com o uso adequado de pinças e outros dispositivos acoplados ao manipulador.

b) Prévio conhecimento das seqüências possiveis de montagem.

É de se esperar que, com este conhecimento, se efetuem simulações das diversas opções 
de seqüência de montagem e das respectivas trajetórias do manipulador.

Esta tendência da automação de processos de montagem beneficia a produção na medida em que reduz os custos, uniformiza os produtos, aumenta a eficiência, elimina os riscos, facilita a inspeção e melhora a qualidade. Ela também influencia diretamente a elevação do padrão de vida da região, quando abre caminho para melhores salários, barateia produtos de boa qualidade, reduz a jornada de trabalho, possibilita aumento da segurança do trabalho e propicia inúmeras outras facilidades.

A implantação de um sistema automatizado requer em geral investimento elevado; para minimizar riscos, é desejável que a automação seja planejada e instalada criteriosamente para que se alcancem os benefícios máximos que poderão advir da sua implantação, tanto para a empresa como para a sociedade (HITOMI K. (4979) [3]).

Ganha assim importância fundamental o conhecimento das seqüências viáveis de montagem, dado o fato de o número de seqüências ser extremamente grande mesmo para quantidade pequena de peças, crescendo exponencialmente com o seu aumento. Diante dos vários problemas que se defronta quando da concepção de um sistema de montagem, os estudos nessa área são bastante numerosos, entre os quais podemos citar um dos mais recentes, cuja abordagem é baseada na teoria dos grafos: And/Or Graph Representation of Assembly Plans (Luiz S. Homem de Mello e Arthur C. Sanderson (1990) [4].

Nosso trabalho procura estabelecer a ordem de operações de montagem baseada na estrutura do produto, numa tentativa de criar métodos que viabilizem a transição da produ- ção tradicional (manual integral ou manual assistido) para a produção automatizada.

\section{A Técnica Utilizada}

O processo aqui apresentado baseia-se no método de BOURJAULT A. (1984) [5] que estabeleceu um modelo matemático para o cálculo de seqüências de montagem. Acopladas a tal método estão utilizadas também as simplificações propostas por FAZIO e WHITNEY (1986) [6], que nos propiciaram a criação de um algoritmo para o cálculo de seqüências de montagem válidas com número maior de peças. Neste trabalho, o objetivo principal é o cálculo das seqüências válidas de montagem, cujo conhecimento permite a escolha da melhor seqüência para utilização num sistema semi-automático ou automático flexível de montagem que envolveria as seguintes etapas de estudo:

a) Análise das seqüências obtidas. Refere-se à análise relativa ao tipo de técnicas necessárias, para a execução das ligações apresentadas nas seqüências, as condições das ligações obtidas (se são estáveis, passíveis, de deformação, fácil execução etc.) ou outras situações que o engenheiro de produção considere necessárias para uma perfeita montagem;

b) redução pelo aumento de restrições: procura-se eliminar as seqüências que não atendam ao critério de eficiência desejado, como por exemplo as ligações instáveis passíveis de deformação, ou aquelas que sejam de dificil execução face a posicionamentos inadequados, falta de equipamentos e outros fatores.

Para a escolha da seqüência ótima, devemos ter em conta que o conceito de ótimo 
varia de empresa para empresa de acordo com o objetivo de cada uma que pode ser o caminho de menor custo, uma melhor qualidade do produto, um menor tempo de execução ou diversos outros critérios ditados pela disponibilidade e pelos objetivos existentes em cada indústria.

No trabalho por nós desenvolvido, o cálculo de sequêencias válidas pode ser utilizado para qualquer produto e tipo de montagem que não envolva submontagens isoladas. $\mathrm{O}$ nosso objetivo maior é, porém, sua aplicação em montagem semi-automática ou automática flexível. O modelo desenvolvido para determinação de seqüências de montagem é baseado na teoria dos grafos. A nomenclatura utilizada neste artigo é encontrada em Harary, (1972) [7] e Guimarães, G (1989) [8], P.O. Boaventura (1979) [9].

\section{Elementos e Definições Necessárias}

O pré-produto é representado por um 1 grafo $G(X, L)$, não orientado, com $n$ vértices (representado as $n$ peças) $\mathrm{l}$ arestas (ligações entre as peças). $\mathrm{O}$ grafo $\mathrm{G}$ é rotulado (seus vértices são identificados) e a identificação dos vértices é feita pelo nome ou código da peça. $G$ é conexo e as cadeias existentes neste grafo caracterizam as seqüências de ligações existentes entre as diversas peças, algumas das quais podem ser associadas a seqüências de montagem.

A transição de uma etapa de montagem para outra é representada por uma operação de compactação de $\mathrm{G}$, até que ele se reduza a um grafo trivial com único vértice correspondente ao produto acabado. Durante estas operações, as arestas superpostas representam ligações que serão executadas simultaneamente, o que só aparecerá se o grafo $\mathrm{G}$ tiver ciclos. Caso contrário, em cada etapa será executada uma e só uma ligação.

Cada seqüência de montagem gerada pelo algoritmo é uma solução do problema, representada por uma árvore orientada, no sentido da ligação inicial (raiz) para a ligação final (folhas). Outras soluções podem ser obtidas dela através de desmontagens, a serem executadas retirando-se as últimas peças que foram colocadas na montagem. Retirar peças de uma montagem equivale a desdobrar vértices reunidos pela operação de compactação desfazendo ligações realizadas, isto é, introduzindo a aresta correspondente a esta ligação, até o ponto em que uma ligação passível de realização não foi utilizada para gerar sequiência. A partir desta ligação, geram-se outras soluções.

O conjunto de soluções é dado por uma floresta onde as raízes (ligações iniciais possiveis) formam uma base.

\section{Métodos de Bourjault e Fazio - Whitney}

O método de Bourjault tem o mérito de formular a idéia principal da modelagem, baseada na representação do produto por um grafo e em um questionário dirigido a cada ligação, sobre a possibilidade de sua realização em determinado estágio. O conjunto de perguntas formuladas permite a obtenção dos estados impedidos da seqüência de montagem, o que torna viável a composição dos estados iniciais possíveis. Ocorre, porém, que a técnica de busca dos estados impedidos é longa e de dificil utilização. A partir da primeira etapa, o processo se torna de aplicação dificil porque exige um grande número de 
perguntas a serem formuladas, variando de acordo com o conjunto a ser montado. A busca das cadeias e das relações para produtos com um gránde número de ligações é impraticável.

O método de Fazio e Whitney é desenvolvido com a utilização inicial das técnicas de Bourjault. Todavia, no estágio das perguntas apresenta um questionário com um número menor de perguntas, as quais são mais abrangentes e envolvem toda a montagem, o que permite a sua utilização para um produto com um maior número de peças. Enquanto Bourjault objetiva a confecção dos estados iniciais possiveis, Fazio e Whitney visam a confecção da lista de precedências. Ambas contêm o mesmo tipo de informações, porém a elaboração desta última é muito mais simples. A partir da lista de precedências, torna-se possível elaborar um algoritmo para o cálculo de seqüências.

\section{Etapas do Método}

A primeira etapa envolve a construção do grafo associado ao produto.

Neste processo, de modo geral as ligações são determinadas com razoável facilidade se a fixação das peças é bem definida (contato físico direto entre as peças, ligação envolvendo somente duas peças). A aparente simplicidade deste conceito pode, porém, provocar erros no levantamento de ligações ou, pelo menos, um aumento desnecessário do seu número, aumentando consideravelmente o trabalho de cálculo das seqüências.

O levantamento das ligações existentes é feito através do manual técnico, ou diretamente a partir da "imagem explodida" do produto. Em qualquer dos casos, podemos nos deparar com ligações mal definidas: ligações indiretas (feitas através de outras peças), inúmeras peças dividindo a mesma fixação, ou ligações móveis. O conceito é flexível, dando liberdade de interpretação (isto é, admite-se incluir ou eliminar ligações) e, quando prudentemente explorado, pode colaborar com a melhoria do processo de cálculo das seqüências, eliminando ligações que não representam uma etapa de trabalho, existindo apenas em função do contato físico.

Um erro por falta de ligações acarretará número menor de seqüências válidas, pois as ligações não computadas deixarão de ser consideradas para a montagem. No caso de se considerarem ligações não existentes, seqüências espúrias serão geradas, aparecendo operações irreais.

Consideramos como componente elementar uma peça única ou um conjunto de peças que, durante toda a montagem, permaneça inalterável. É o caso em que esse conjunto é montado em outro departamento, ou mesmo adquirido como produto acabado, constituindo para a atual montagem um bloco único que pode ser considerado como peça única. Ele será ligado a outra peça, ou a uma submontagem, dependendo da ordem da seqüência. $O$ produto, ao ser elaborado, admite pelo menos uma seqüência de montagem, correspondente à existência de uma cadeia que una todos os vértices, sem sua repetição e, pelo menos, uma tarefa inicial que não impeça a realização das demais. O grafo pode ser uma árvore se envolver uma e somente uma ligação por etapa, caso contrário, haverá ciclos. Nestes casos, a montagem apresenta algumas fases onde mais de uma ligação é executada.

A confecção da lista de precedências é um ponto importante para o cálculo das seqüências de montagem, pois a sua composição de 
forma compacta e precisa agiliza a utilização do algoritmo.

As simplificações adotadas, no método de Bourjault, por Fazio e Whiney são obtidas a partir do questionário elaborado para cada ligação que permite gerar a lista de precedências. A lista de precedências, imposta pela montagem, é o conjunto de restrições, isto é, nele a execução de uma ligação precederá outra, sempre que a ordem inversa torne a montagem irrealizável. Para cada ligação $L_{i}, 1$ $<-i<-1$, as seguintes questões são formuladas:

$Q_{1}$ ) Quais ligações devem ser realizadas antes de $L_{i}$ ?

As questões do tipo $Q_{1}$ identificam as ligações $L_{i}$ que são executadas antes da execução de $L_{i}$. As ligações que precedem $L_{i}$ são aquelas que teriam sua execução impedida após feita Li.

$\mathrm{Q}_{2}$ ) Quais ligações devem ser realizadas após a execução de $L_{i}$ ?

As ligações do tipo $\mathrm{Q}_{2}$ identificam as ligações $L_{j}$ que são executadas após a execução de $L_{i}$. As ligações que sucedem $L_{i}$ são aquelas que impedem a execução de $L_{i}$.

As questões do tipo $Q_{1}$, cuja resposta for "nenhuma", não geram procedência. Caso contrário, a precedência existe e é representada na forma:

$$
\mathrm{L}_{\mathrm{j}} \text { ou } \mathrm{L}_{\mathrm{k}} \longrightarrow \mathrm{L}_{\mathrm{i}}
$$

As questões do tipo $Q_{2}$, cuja resposta for "nenhuma", não geram precedência. Caso contrário, a precedência existe e é representada na forma:

$$
\mathrm{L}_{\mathrm{i}} \longrightarrow \mathrm{L}_{\mathrm{s}} \mathrm{eL}_{\mathrm{i}}
$$

A confecção da lista de precedências é dependente do grafo representativo de montagem. Os ciclos existentes e as ligações que eles determinam devem ser consideradas para que não se gerem precedências contraditórias. É necessário que no estudo das precedências fique assegurado que a realização de mais de uma ligação numa mesma etapa não gere impossibilidades de montagem.

Ao se fazer a lista de precedências questionando cada ligação $L_{i}$ com as perguntas da forma $Q_{1}$ e $Q_{2}$, é preciso que se tenha a visão completa da montagem, para evitar que, a partir de certo estágio, ela fique impossibilitada de prosseguir, isto é, torna-se necessário que se tenha uma visão completa da montagem para saber se a ligação questionada impede a execução de qualquer outra.

As seqüências de montagem consideradas válidas neste trabalho obedecem a regras impostas pelas restrições de montagem do próximo produto, isto é, se uma ligação executada impede a realização das demais ligações, existirão restrições relativas a estas ligações na lista de precedências.

O algoritmo foi elaborado a partir da visualização do produto a ser montado através do grafo. Os vértices representam as peças por montar, e as arestas, as ligações a serem executadas. A execução de uma ligação indica a união de duas peças; a aresta relativa a esta ligação já não existe, pois as duas peças são agora uma submontagem correspondente nografo a um único vértice. Ografo resultante possui, pelo menos, uma aresta e um vértice a menos.

A primeira ligação da seqüência válida é escolhida entre as que não impedem ligações subseqüentes. Pode existir mais de uma ligação nesta situação, o que indica que haverá sequiências começadas por todas estas liga- 
ções. Estas ligações formam a base do conjunto de soluções.

Como foi explicado anteriormente, a composição de novas seqüências de montagem é feita do final para o principio. Cada grafo compactado representa, através dos vértices compactados, as peças da submontagem já executada. Os demais vértices e arestas definem o trabalho a ser realizado, isto é, as ligações que precisam ainda ser feitas com a respectiva colocação de peças até que, no final do processo, obtenhamos um grafo com apenas um vértice que representa o produto acabado.

As ligações seguintes à primeira são obtidas no grafo somente entre as arestas adjacentes que compartilham o vértice compactado. Entre estas será executada uma ligação que não possua precedências.
Durante o processo de montagem, o grafo é reduzido a um só ponto tantas vezes quantas forem as seqüências válidas calculadas, retornando à situação inicial, com todos os vértices e arestas, só quando é trocada a ligação inicial. É possível decompor o problema geral em problemas menores, fazendo-se o cálculo das seqüências válidas por etapas, isto é, se existirem $\mathrm{k}$ ligações possíveis de iniciar o processo de montagem, calculam-se as seqüências válidas iniciadas com cada uma delas.

\section{Exemplo de uma AplicaçãoPrática}

Oexemplo considerado representa um problema de montagem de um carburador. Os elementos usados para fixação das ligações não foram considerados como componentes elementares, logo não foram representados por vértices no grafo (Fig. 1)

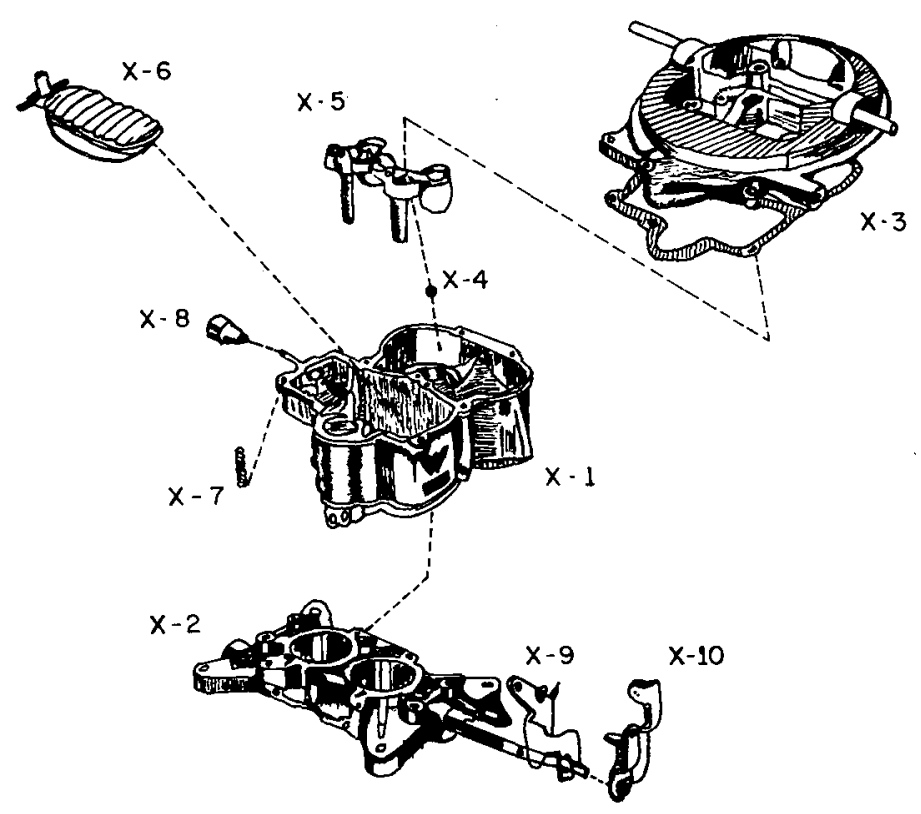


Foram considerados $n=10$ componentes elementares (peças) e $1=12$ ligações $(\log 0,1>n-1)$.

A cuba (vértice $X_{1}$ ) é uma peça única indivisível que não apresenta dúvidas por ser um componente elementar. Neste mesmo caso se encontram as peças esfera $\left(X_{4}\right)$; mola $\left(X_{7}\right)$ e estilete $\left(X_{8}\right)$.

A tampa $\left(\mathrm{X}_{9}\right)$ já necessita de definições sobre o que será o componente elementar. É composta de várias partes, porém sua montagem não é executada com as demais peças, pois para sua confecção são necessárias técnicas especiais não disponiveis no local de montagem. É adquirida praticamente pronta. Optamos por considerar toda parte adquirida como componente elementar. Outras peças que estão neste caso são: suporte $\left(X_{\zeta}\right)$, boia $\left(X_{6}\right)$, braço do acelerador $\left(X_{9}\right)$ e braço do injetor $\left(\mathrm{X}_{10}\right)$. Estas peças necessitam de montagens especiais que não comportariam na montagem geral, por serem detalhadas demais.

As ligações fáceis de definir são as $L_{1}, L_{2}$ (após a definição do componente elementar), $\mathrm{L}_{3}$ (idem), $\mathrm{L}_{4}, \mathrm{~L}_{5}, \mathrm{~L}_{6}, \mathrm{~L}_{9}, \mathrm{~L}_{10}, \mathrm{~L}_{11}, \mathrm{~L}_{12}$. Por outro lado, a $L_{7}$ é uma ligação feita indiretamente através da peça $X_{3}$ (tampa). Consideramos a $\mathrm{L}_{7}$ executada quando a cuba é colocada na base, porém sua fixação só é feita quando se prende a tampa. Qualquer seqüência executada na horizontal, em que se coloca primeiro a base e depois a cuba (utilizando a gravidade) é boa prática: as demais seriam ineficientes. A $\mathrm{L}_{8}$ é também uma ligação indireta, pois não há contato físico da tampa $\left(X_{9}\right)$ com a base $\left(X_{2}\right)$. $O$ contato é feito através do parafuso que fixa ambas. Existe ligação entre o braço do injetor e o braço do acelerador mas não foi considerada devido ser a mesma resultante de um contato físico que não depende de processo de fixação.
Após a definição das peças, ligações e grafo correspondente, foi aplicado para cada ligação $L_{\mathrm{i}}$ um questionário com perguntas dos tipos $\mathrm{Q}_{1} \in \mathrm{Q}_{2}$. Estas questões são assim formuladas:

Questionário com perguntas do tipo $\mathrm{Q}_{\text {}}$ :

$Q_{1}$ - Que ligações devem ser (obrigatoriamente) feitas antes de se fazer $L_{i}$ ?

$i=1$ Nenhuma ligação deve ser feita antes de $L_{1}$

$\mathrm{i}=2$ Antes de unir as peças $\mathrm{X}_{5}$ e $\mathrm{X}_{1}$, isto é, executar a ligação $L_{2}$, a peça $X_{4}$ já deve estar unida a $X_{1}$. A ligação $L_{1}$ precede a $L_{2}$.

\section{$1---->2$}

$i=3$ Nenhuma ligação precisa ser feita antes de 13 .

$i=4$ Antes de colocar a peça $X_{7}$ em $X_{1}$, é necessário que a peça $X_{6}$ esteja em $X_{1}$. A ligação $L_{3}$ deve ser executada antes de $L_{4}$.

$$
3--->>4
$$

$i=5$ A colocação da peça $X_{8}$ em $X_{1}$ impede a colocação da peça $X_{6}$ em $X_{1}$. A ligação 3 deve ser efetuada antes da ligação $L_{5}$.

\section{$3-\cdots>5$}

$\mathrm{i}=6$ Para a peça $\mathrm{X}_{1}$ ser ligada a peça $\mathrm{X}_{2}$, todas as peças internas devem estar colocadas. $\mathrm{L}_{1}$ e $\mathrm{L}_{2}$ e $\mathrm{L}_{3}$ e $\mathrm{L}_{4}$ devem estar prontas.

1 e 2 e 3 e 4 -----> 6 como

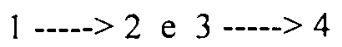

2 e 4 -..-> 6 
$i=7$ Nenhuma ligação precisa ser feita antes de $L_{7}$.

$i=8$ Colocar a peça $X_{2}$ na peça $X_{3}$ impede a colocação da peça $\mathrm{X}_{1}$. É necessário que $\mathrm{L}_{6} \mathrm{e}$ $\mathrm{L}_{7}$ já estejam prontas.

$$
6 \text { e } 7 \text {-----> } 8
$$

$i=9$ Nenhuma ligação precisa ser feita antes de $\mathrm{L}_{9}$.

$\mathrm{i}=10 \mathrm{~A}$ peça $\mathrm{X}_{10}$ ligada a $\mathrm{X}_{2}$ impede a colocação da peça $X_{9}$. A ligação $L_{9}$ deve estar pronta.

$$
\text { 9-----> } 10
$$

$\mathrm{i}=11 \mathrm{~A}$ peça $\mathrm{X}_{9}$ ligada a $\mathrm{X}_{3}$ impede a colocação da peça $\mathrm{X}_{2}$. As ligações $\mathrm{L}_{7}, \mathrm{~L}_{8} \mathrm{e} \mathrm{L}_{9}$ devem estar prontas.

\section{7 e 8 e 9 -.-.> 11}

$\mathrm{i}=12$ Colocar a peça $\mathrm{X}_{10}$ na $\mathrm{X}_{3}$ impede a colocação da peça $\mathrm{X}_{2} \mathrm{e} \mathrm{X}_{9}$. As ligações $\mathrm{L}_{7}, \mathrm{~L}_{9}$. $\mathrm{L}_{10}$ e $\mathrm{L}_{11}$ devem estar prontas.

$$
7 \text { e } 9 \text { e } 10 \text { e } 11 \text {----> } 12
$$

Questionário com perguntas do tipo $\mathrm{Q}_{2}$

$\mathrm{Q}_{2}$ - Quais ligações devem ser deixadas para fazer depois de $L_{i}$ ?

$i=1$ As peças $X_{3}$ e $X_{5}$ colocadas na $X_{1}$ impedem a colocação de $X_{4}$. As ligações $L_{2} e$ $\mathrm{L}_{6}$ devem ser executadas após a ligação $\mathrm{L}_{1}$.

$$
\begin{aligned}
& 1-\ldots>2 ; 1 \ldots>6 \text { como } 2--->>6 \\
& 1--->>2
\end{aligned}
$$

$\mathrm{i}=2$ A peça $\mathrm{X}_{3}$ colocada na $\mathrm{X}_{1}$ impede $\mathrm{a}$ colocação da peça $X_{5}$ na peça $X_{1}$. A ligação $L_{6}$ deve ser executada após $L_{2}$.

$$
2---->6
$$

$\mathrm{i}=3$ As peças $\mathrm{X}_{3}, \mathrm{X}_{7}$ e $\mathrm{X}_{8}$ colocadas na $\mathrm{X}_{1}$ impedem a colocação da peça $X_{6}$ na $X_{1}$. As ligações $L_{4}, L_{5}$ e $L_{6}$ devem ser deixadas para execução após a ligação $\mathrm{L}_{3}$.

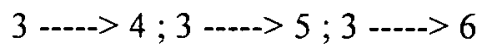

como 4 -----> 6 resulta que

$$
3---->4
$$

$3---->5$

$i=4$ A colocação da peça $X_{3}$ em $X_{1}$ impede a colocação da peça $X_{7}$ em $X_{1}$. A ligação $L_{6}$ deve ser feita após a ligação $L_{4}$.

$$
4---->6
$$

$\mathrm{i}=5$ Nenhuma ligação deve ser executada após a ligação $\mathrm{L}_{5}$.

$i=6$ A ligação das peças $X_{1}$ e $X_{3}$ fica impedida se as peças $X_{2}$ e $X_{3}$ já estiverem unidas. A ligação $L_{8}$ deve ser executada após a ligação $L_{6}$.

$$
6-\ldots>8
$$

$i=7$ A ligação das peça $X_{1}$ e $X_{2}$ fica impedida se as peças $X_{2}$ e $X_{3}$ já estiverem unidas, assim como $X_{9}$ e $X_{3}$. As ligações $L_{8}$, $L_{11}$ e $L_{12}$ devem ser executadas após $L_{7}$.

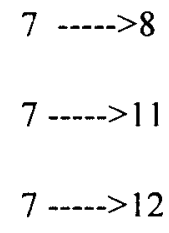


$i=8$ A colocação da peça $X_{9}$ na $X_{3}$ impede a colocação da peça $X_{2}$. A ligação $L_{11}$ deve ser executada após $L_{8}$.

$$
8---->11
$$

$\mathrm{i}=9$ A ligação das peças $\mathrm{X}_{2}$ a $\mathrm{X}_{10^{\prime}}$ assim como a ligação das peças $X_{3}$ a $X_{9}$ e $X_{3}$ a $X_{10^{\prime}}$ impedem a ligação $L_{9}$. As ligações $L_{10} L_{11} e$ $\mathrm{L}_{12}$ devem ser executadas após a ligação $\mathrm{L}_{9}$.

$$
\begin{aligned}
& 9--->>10 \\
& 9--->>11 \\
& 9---->12
\end{aligned}
$$

$\mathrm{i}=10$ A ligação das peças $\mathrm{X}_{3}$ e $\mathrm{X}_{10}$ impedem a ligação das peças $X_{2}$ e $X_{10}$. $A$ ligação $L_{12}$ deve ser executada após a ligação $L_{10}$.<smiles>[12OH]</smiles>

$\mathrm{i}=11$ A colocação da peça $X_{10}$ impede a colocação da peça $X_{9}$. A ligação $L_{12}$ deve ser executada após a $L_{11}$.

$$
11-\cdots>12
$$

$i=12$ Nenhuma ligação deve ser feita após a ligação $L_{12}$.

Lista de precedências:

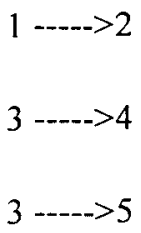

2 e 4 -.--> $>6$

6 e 7 --.-->8

$$
9--->>10
$$

7 e 8 e 9 ----->11

7 e 9 e 10 e $11--->12$

Pela lista de precedências obtida, verificase que as ligações que permitem começar a montagem são as ligações $\mathrm{L}_{1}, \mathrm{~L}_{3}, \mathrm{~L}_{7}$ e $\mathrm{L}_{9}$. As que serão executadas no final da montagem são as ligações $\mathrm{L}_{5}$ e $\mathrm{L}_{12}$.

Pode ocorrer durante uma montagem que determinadas ligações, isoladamente, não impeçam uma outra ligação mas que em conjunto o façam, o que geraria sentenças da forma:

$$
\text { A ---->B e C }
$$

A sentença lógica que representa esta precedência não se enquadra nas sentenças lógicas utilizadas nesta técnica. Para evitar usos indevidos, sempre que restrições deste tipo surgirem, é boa prática impor restrições que anulem sua execução. Neste caso, pode-se impor que $\mathrm{L}_{\mathrm{A}}$ seja executada antes de $\mathrm{L}_{\mathrm{B}}$ e $\mathrm{L}_{\mathrm{C}}$ ou entre ambas.

Com esta lista de precedências utilizamos o algoritmo programado e calculamos 2392 seqüências válidas de montagem.

Após a obtenção deste total, é possivel restringir as seqüências (por exemplo, por algum detalhe técnico) às que se iniciem por uma peça dada. Para poder avaliar a influência desse tipo de restrição, apresentamos (itens 1 a 4 abaixo) a subdivisão das 2392 seqüências em grupos nos quais a peça inicial é sempre a mesma. Nesta contagem, considera-se que a montagem possa ser feita com as peças em qualquer posição. Isto, no entanto, pode gerar problemas práticos como p. ex., problemas na 
fixação dos componentes. Por essa razão, nos itens seguintes nos restringimos a seqüências organizadas de tal forma que a montagem seria executada sobre uma mesa (na horizontal), o que impede a realização de seqüências ao inverso, as ligações sendo prioritariamente executadas sobre cada peça já colocada. No item 5 a primeira peça pode $\operatorname{ser} X_{1}$ (cuba) ou $X_{2}$ (base), o que permite o início por $\mathrm{L}_{7}$ ou $\mathrm{L}_{9}$, enquanto no item 6 somente a cuba foi considerada como inicial, admitindo apenas $L_{7}$ como ligação inicial.

1) Seqüências iniciadas pela ligação $L_{1}$--$-->616$

2) Seqüências iniciadas pela ligação $\mathrm{L}_{3}$--$\rightarrow>840$

3) Seqüências iniciadas pela ligação $\mathrm{L}_{7}$--$-->728$

4) Sequêências iniciadas pela ligação $L_{9}$-.$-->208$

5) Seqüências executadas na horizontal -$-.->390$

6) Caso anterior, começando pela cuba --$-->182$

\section{Observações Finais e Conclusões.}

A técnica aqui discutida e exemplificada permite a geração de conjuntos de seqüências viáveis para operações de montagem automatizadas por meio de manipuladores programáveis ("robôs"). Uma estrutura do grafo é usada como suporte para o funcionamento do algoritmo gerador de seqüências, o qual utiliza ainda informações sobre a precedência das ligações a serem feitas.
O uso de restrições adicionais, como a fixação da peça inicial da montagem ou da posição em que esta deve ser feita, limita o número de seqüências viáveis e permite conclusões sobre as maiores ou menores limitações trazidas ao processo por essas restrições.

Através de valorações atribuídas aos componentes da estrutura é possível, em princípio, classificar as seqüências por valor com vistas à definição eventual de uma seqüência ótima; no entanto, uma valoração adeqüada a esse fim exige não apenas o conhecimento dos detalhes do equipamento a ser montado mas, ainda, dos associados ao próprio manipulador programável a ser usado, o que a torna essencialmente específica de cada montagem em particular. $O$ desenvolvimento de regras que possibilitem a definição de valorações com um real significado prático é, portanto, um trabalho da ordem de grandeza do que serviu de base ao texto acima e se constitui em um campo aberto de pesquisa.

\section{Referências \\ Bibliográficas}

[1] NEVINS J. L. and WHITNEY, D. Computer-Controlled Assembly, Scientific American, Vol. 238, no 2, 62-74 (1978).

[2] NAVEIRO, R. M. Automação da Produção e Projeto do Produto, mimeo (1987).

[3] HITOMI, K. Manufacturing Systems Engineering, Taylor and Francis Ltda, London (1979).

[4] HOMEM DE MELO, Luiz S. and SANDERSON, Arthur C.And/Or Graph Representation of Assembly Plans, IEEE Tran- 
sactions on Robotics and Antomation, Vol. 6, no 2, april (1990).

[5] BOURJAULT, A.Contribution à une Aproche Metodologique de l, Assemblage Automatisé, Tese de doutorado, Universidade de France-Comté (1984).

[6] FAZIO, T. and WHITNEY, D. Simplifiel Generation of all Mechanicl Assembly Sequences, CSDL-P-2709, The Charles Stark Draper Laboratory, Inc., Cambridge, Massachusetts, June (1986).
[7] HARARY, F. Graph Theory, AddisonWesley, Reading, Mass., (1969).

[8] GUIMARÃES, G. Seqüência Automática de Montagem, Tese de Mestrado, COPPE/UFRJ, (1989).

[9] BOA VENTURA, P.O.Teoria e Modelos de Grafos, Etidora Edgard Blucher Ltda, São Paulo (1979). 